\title{
Transapical approach for myectomy in hypertrophic cardiomyopathy
}

\author{
Kunal D. Kotkar, Sameh M. Said, Hartzell V. Schaff \\ Department of Cardiovascular Surgery, Mayo Clinic, Rochester, MN, USA \\ Correspondence to: Sameh M. Said, MD. Mayo Clinic, $2001^{\text {st }}$ St SW, Rochester, MN 55905, USA. Email: said.sameh@mayo.edu.
}

Submitted Apr 20, 2017. Accepted for publication May 19, 2017.

doi: $10.21037 /$ acs.2017.06.02

View this article at: http://dx.doi.org/10.21037/acs.2017.06.02

\section{Introduction}

\section{Clinical vignette I}

A 61-year-old woman is a known case of hypertrophic cardiomyopathy (HCM) for three years. She has symptoms of breathlessness on exertion and fatigability. Her echocardiogram shows a mid-ventricular variant of HCM with an aneurysmal apical pouch. There is a midventricular gradient of $30-40 \mathrm{mmHg}$. There is no evidence of subaortic obstruction. We advised a trans-apical mid ventricular myectomy with apical pouch repair.

\section{Clinical vignette II}

A 59-year-old man is known case of HCM for 10 years. Over the last year, his symptoms of shortness of breath and fatigability have steadily progressed. Currently he is unable to work and says that he has to nap in the afternoon if he does any activity in the morning. His echocardiogram shows a hyperdynamic left ventricular function with a small left ventricular cavity; the left ventricular enddiastolic dimension is $41 \mathrm{~mm}$. The small ventricle is confirmed on MRI where the estimated stroke volume index is $24 \mathrm{~mL} / \mathrm{m}^{2}$. There is no evidence of left ventricular outflow tract obstruction, rather his problem is diastolic heart failure related to small left ventricular cavity size. We proposed trans-apical left ventricular myectomy to enlarge the left ventricle cavity.

\section{Surgical technique}

\section{Preparation}

Transapical myectomy is performed with the patient in supine position through a median sternotomy. After central aortic cannulation and two-stage venous cannulation in the right atrium, cardiopulmonary bypass is instituted under normothermia at $2.4 \mathrm{~L} / \mathrm{min} / \mathrm{m}^{2}$. Myocardial protection is achieved using antegrade cold blood cardioplegia solution (1,000-1,200 mL).

\section{Exposition}

Before commencing cardiopulmonary bypass, the left ventricle is assessed using intraoperative echocardiography. In patients with midventricular obstruction, pressure gradient by direct measurement of intra-cardiac and aortic pressures is essential in order to guide adequacy of myectomy. Patients who have apical HCM do not have outflow tract or intracavitary gradients, and pressure measurements are unnecessary. In these patients, adequacy of operation is guided by visual inspection of the ventricle as the cavity is enlarged by removing muscle.

\section{Operation}

A moist laparotomy pad is placed behind the LV, and the apex of the heart is delivered anteriorly (Figure 1). After identifying the left anterior descending artery (LAD), an apical ventriculotomy, approximately $6 \mathrm{~cm}$, is made lateral to it (Figure 2). This incision is located over the apical dimple when one is present (apical pouch), and should be situated far enough to the left of the LAD to allow secure closure of the ventricle without damaging the vessel.

Patients with midventricular obstruction usually have an adequate apical chamber. A cardiotomy sucker is used to displace the posterior medial papillary muscle away from the septum. We look for the endocardial scar on the 


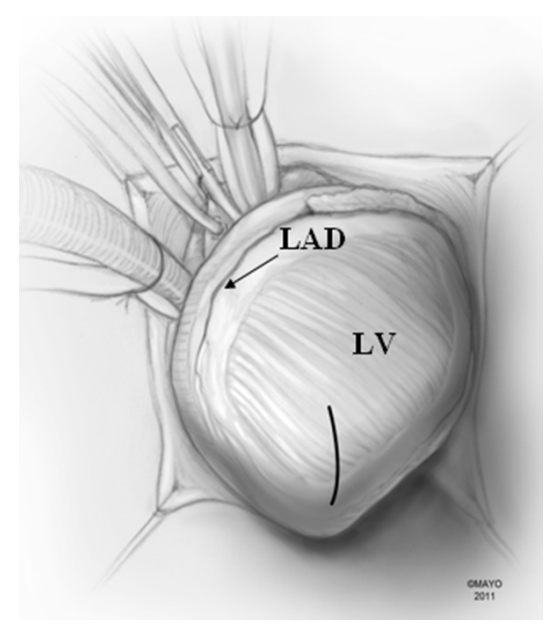

Figure $1 \mathrm{~A}$ moist laparotomy pad is placed in the pericardial well behind the left ventricle, and the apex of the heart is delivered anteriorly. Solid and line show the location of the apical myectomy incision, lateral to the $\mathrm{LAD}$. $\mathrm{RV}$, right ventricle; $\mathrm{LAD}$, left anterior descending coronary artery; LV, left ventricle.

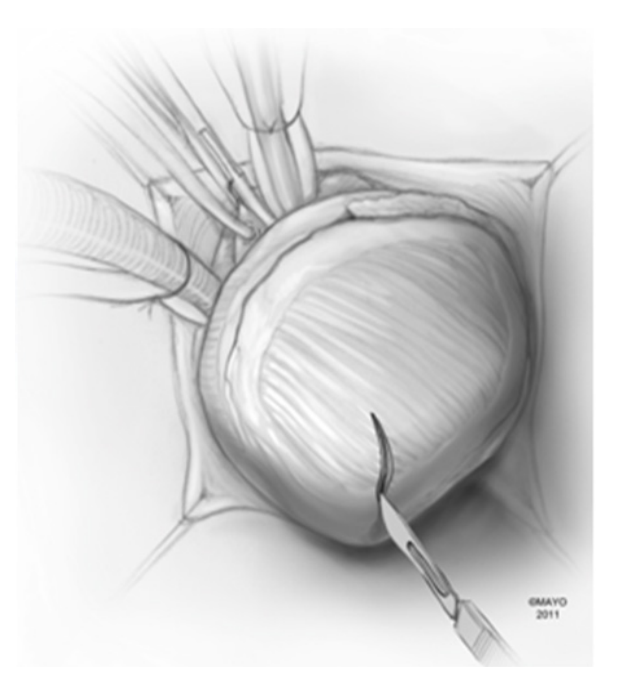

Figure 2 The left anterior descending coronary artery (LAD) is identified, and an apical ventriculotomy is made lateral to it. This incision is located over the apical dimple when one is present (apical pouch), and it should be situated far enough to the left of the LAD to allow secure closure of the ventricle without compromise of the vessel. LAD, left anterior descending coronary artery; LV, left ventricle.

septum in the area of apposition with the papillary muscles, which make contact with the septum during systole and produce the gradient. Myectomy begins in the septum with

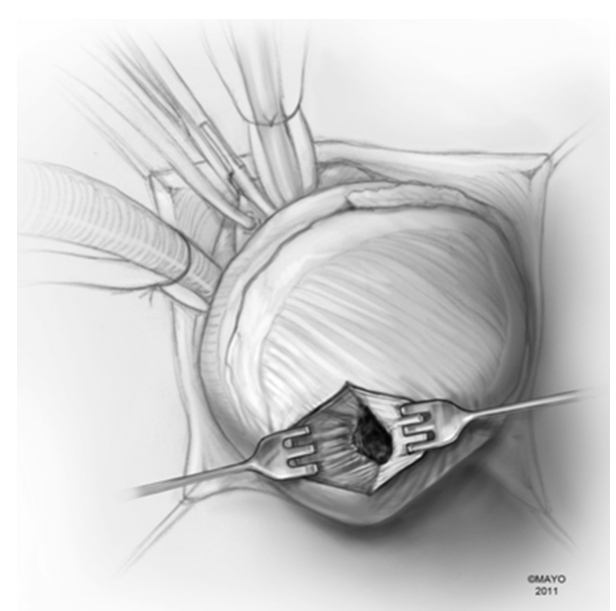

Figure 3 In apical hypertrophic cardiomyopathy, the left ventricular apex is usually obliterated by hypertrophied muscle, and care should be taken not to injure the papillary muscles and mitral valve apparatus.

removal of the endocardial scar and muscle below. Enlarged papillary muscles with mid-ventricular apposition can be shaved as well.

In apical HCM, the LV apex is usually obliterated by hypertrophied muscle, and papillary muscles are displaced apically. There is risk of injury to the papillary muscles and mitral valve apparatus when the ventricle is opened (Figure 3). The myectomy is performed with the main goal of augmenting the LV cavity by removing septal muscle. This is usually done using a combination of No. 10 blade knife and scissors with the aid of small Volkmann retractors (Figure 4). The main focus of the procedure is on the ventricular septum with some shaving done on the $L V$ free wall (Figure 4 inset). Hypertrophied papillary muscles can be shaved to further enlarge the chamber and reduce risk of midventricular obstruction (Figure 5). The adequacy and proximal extent of the resection is evaluated by direct inspection and digital palpation.

The LV is irrigated to remove any debris or particulate matter, and the mitral valve apparatus is inspected to ensure that there has been no injury to it (Figure 6). Excessive shaving of the LV wall near the ventriculotomy may create difficulty in closure or an iatrogenic ventricular septal defect (VSD).

\section{Completion}

The apical ventriculotomy is closed in two layers using 


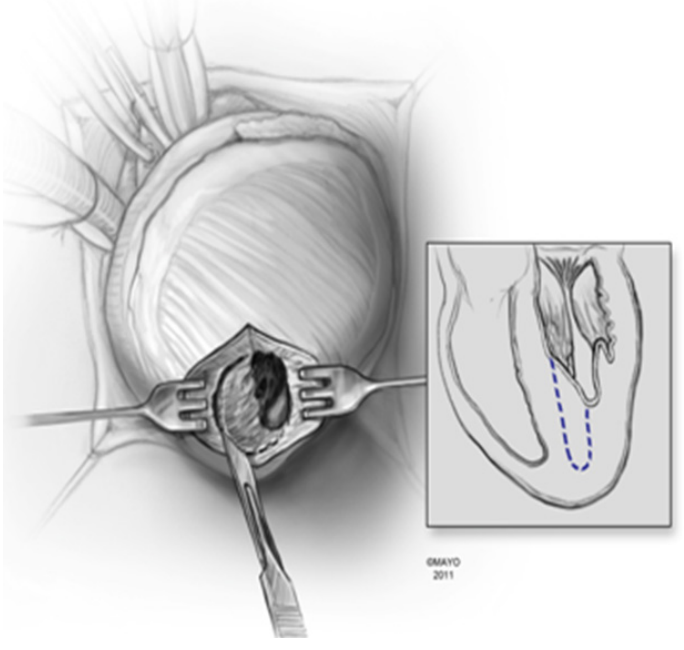

Figure 4 Myectomy is performed removing septal muscle using No. 10 blade knife and scissors with the aid of small Volkmann retractors. The main focus of the procedure is on the ventricular septum with very little shaving done on the LV free wall (dashed line in the inset).

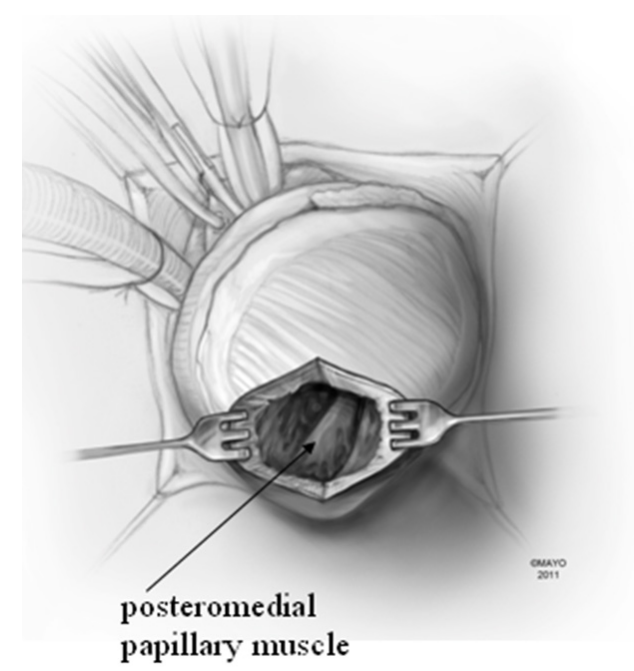

Figure 5 One can visualize the papillary muscles (solid arrow) and the chordae while looking through the ventriculotomy after the myectomy has been completed, and the papillary muscles can be shaved to further increase left ventricular volume and reduce risk of midventricular obstruction.

strips of teflon felt; the first is a running mattress suture of number 1-Ethibond, and the second is an over-andover 0-prolene (Figure 7). The heart is de-aired through the tack vent placed on aspiration and the aortic cross-

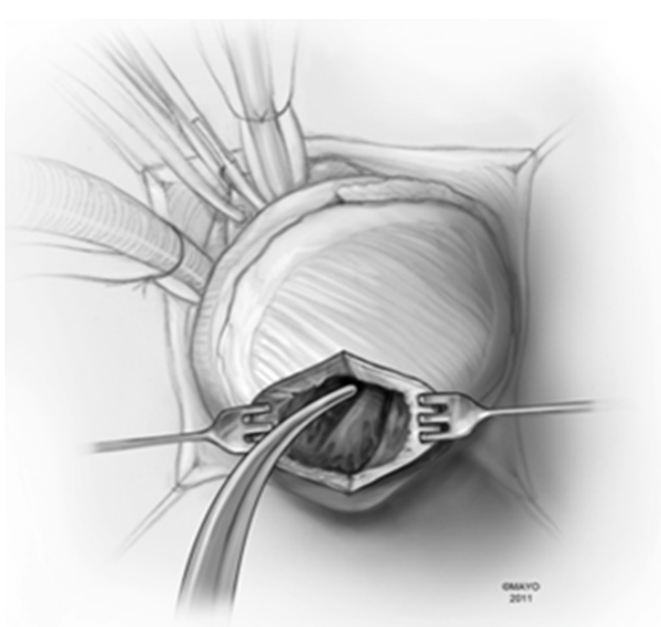

Figure 6 The left ventricle is irrigated to remove any debris or particulate matter, and the mitral valve apparatus is inspected to ensure that there has been no injury to it. The resection removes the mass of the myocardium occupying the left ventricular apex; thereby, augmentation of the left ventricular cavity is achieved.

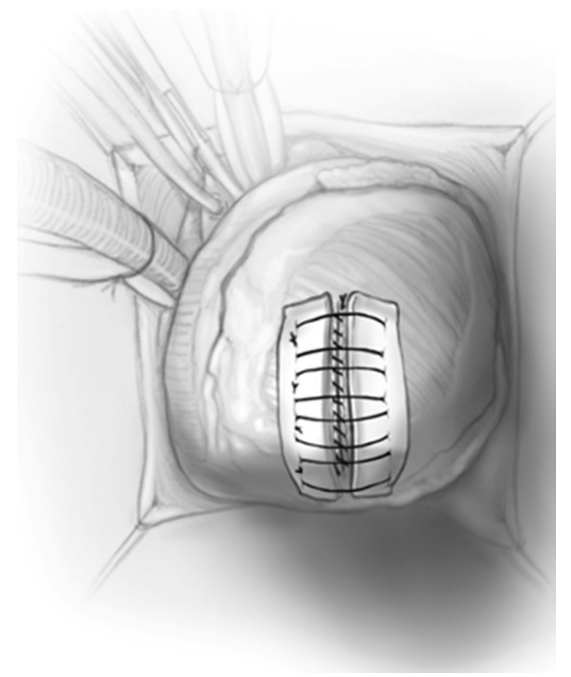

Figure 7 We prefer a two-layer closure of the apical ventriculotomy using strips of teflon felt; the first is a running mattress suture of number 1-Ethibond, and the second is an overand-over 0-prolene.

clamp is removed. After sinus rhythm is achieved, cardiopulmonary bypass is discontinued in the standard fashion. In cases of midventricular obstruction, the left ventricular-to-aortic pressure gradient is re-measured; we routinely go back on pump if there is residual gradient of more than $15-20 \mathrm{mmHg}$. 


\section{Comments}

\section{Clinical results}

Between September 1993 and 2012, transapical approach for apical and midventricular HCM was used in a total of 115 patients (1). All patients with midventricular obstruction $(n=55)$ had relief of their gradient and no patient developed a VSD. Also, we have not observed complications of left ventriculotomy such as $L V$ pseudoaneurysm or ventricular arrhythmias.

\section{Caveats}

The apical incision and its closure produce an area of akinesia, but this is relatively small and does not lead to significant systolic dysfunction. Indeed, in patients with apical HCM, the apex is obliterated with muscle and does not contribute to LV stroke volume (1).

\section{Advantages}

We have used the transapical incision for the following:

(I) Left ventricular enlargement in those patients with the nonobstructive apical variant, with a very small left ventricular cavity and diastolic dysfunction. Transapical myectomy increases LV stroke volume, producing a larger LV end-diastolic volume at lower end-diastolic pressure, thus improving left ventricular compliance (2).

Cite this article as: Kotkar KD, Said SM, Schaff HV. Transapical approach for myectomy in hypertrophic cardiomyopathy. Ann Cardiothorac Surg 2017;6(4):419-422 . doi: 10.21037/acs.2017.06.02
(II) Midventricular obstruction that cannot be safely reached from a transaortic approach. The transapical approach provides excellent exposure of the mid-ventricle for relief of obstruction in this area.

(III) Patients who have diffuse septal hypertrophy where a combined transaortic and transapical approach are required to ensure complete relief of the obstruction.

\section{Acknowledgements}

None.

\section{Footnote}

Conflicts of Interest: The authors have no conflicts of interest to declare.

\section{References}

1. Said SM, Schaff HV, Abel MD, et al. Transapical approach for apical myectomy and relief of midventricular obstruction in hypertrophic cardiomyopathy. J Card Surg 2012;27:443-8.

2. Schaff HV, Brown ML, Dearani JA, et al. Apical myectomy: a new surgical technique for management of severely symptomatic patients with apical hypertrophic cardiomyopathy. J Thorac Cardiovasc Surg 2010;139:634-40. 